\title{
The prevalence of hereditary hemorrhagic telangiectasia in Juvenile Polyposis syndrome patients with SMAD4 mutations
}

\author{
Margaret O'Malley ${ }^{1 *}$, Lisa LaGuardia', Matthew Kalady', Joe Parambil², Brandie Leach ${ }^{3}$, Charis Eng ${ }^{3}$, James Church', \\ Carol Burke ${ }^{1}$
}

From 14th Annual Meeting of the Collaborative Group of the Americas on Inherited Colorectal Cancer Dallas, TX, USA. 12-13 October 2010

\section{Background}

Juvenile Polyposis Syndrome (JPS) is defined by the presence of $\geq 5$ colorectal juvenile polyps or any number of juvenile polyps in an individual with a family history of JPS. Genetic alterations including either point mutations or large rearrangements in $B M P R 1 A$ or $S M A D 4$ are found in $50 \%$ of affected individuals. Hereditary Hemorrhagic Telangiectasia (HHT) is an autosomal dominant disease diagnosed upon the presence of epistaxis, visceral arteriovenous malformations (AVM) or mucutaneous telangiectasias. HHT is diagnosed when there are $\geq 3$ manifestations and is suspected when there are at least 2 manifestations. Most HHT cases are caused by a germline mutation in $A L K 1$ or ENG, members of the TGF $\beta$ signaling pathway. Approximately $22 \%$ of patients with Juvenile Polyposis Syndrome (JPS) due to a SMAD4 mutation have been reported to also have HHT [1]. Most prior publications have few patients and no systematic approach to screening, so the true incidence of the combined JPS/HHT syndrome is not known. Our aim was to determine the prevalence of HHT in our patients with JPS with a SMAD4 mutation including those who underwent systematic screening for AVM's.

\section{Methods}

JPS patients were identified from a comprehensive polyposis database using Cologene $\odot$ software. Families carrying a germline SMAD4 mutation were studied by screening affected patients for cutaneous telangiectases and with

\footnotetext{
* Correspondence: omallem@ccf.org

'The Sanford R. Weiss, M.D, Center for Hereditary Colorectal Neoplasia, Digestive Diseases Institute, Desk A30, 9500 Euclid Ave., Cleveland Clinic, Cleveland, OH 44195, USA

Full list of author information is available at the end of the article
}

cardiac bubble ECHO, CAT scan chest, or MRI of brain for other AVMs.

\section{Results}

Fourteen of 38 JPS families underwent genetic testing. Nine families were identified to have a SMAD4 mutation. These families include 21 affected relatives, 11 men and 10 women, with a current mean age of 36.3 years (range $4-70$ ). Fourteen affected relatives, from 6 families, underwent HHT screening $(7$ men and 7 women, with a mean age of 35.4 years (range 15-70). Eleven of 14 (79\%) had $\geq 3$ HHT manifestations and two of $14(14 \%)$ had at least 2 . In addition, 3 of 7 unscreened affected relatives have presented with at least 2 manifestations of HHT. Of the 24 families that have not had genetic testing or HHT screening one affected family member presented with $\geq 3$ HHT manifestations, and two had at least 2 manifestations.

\section{Conclusion}

Greater than $90 \%$ of our patients with JPS due to SMAD4 mutations had clinically diagnosed or suspected HHT. Genetic testing should be performed in all JPS patients. In addition, systematic HHT screening is recommended for JPS patients with SMAD4 mutations.

\footnotetext{
Author details

${ }^{1}$ The Sanford R. Weiss, M.D, Center for Hereditary Colorectal Neoplasia, Digestive Diseases Institute, Desk A30, 9500 Euclid Ave., Cleveland Clinic, Cleveland, $\mathrm{OH}$ 44195, USA. ${ }^{2}$ Respiratory Institute, Cleveland Clinic, 9500 Euclid Ave., Cleveland, OH 44195, USA. ${ }^{3}$ Genomic Medicine Institute, 9500 Euclid Ave., Cleveland Clinic, Cleveland, OH, 44195, USA.
}

Published: 10 March 2011 


\section{Reference}

1. Aretz S, Stienen D, Uhlhaas S, Stolte M, Entius MM, Loff S, Back W, Kaufmann A, Keller KM, Blaas SH, Siebert R, Vogt S, Spranger S, HolinskiFeder E, Sunde L, Propping P, Friedl W: High proportion of large genomic deletions and a genotype-phenotype update in 80 unrelated families with juvenile polyposis syndrome. Journal of Medical Genetics 2007, 44:702-709.

doi:10.1186/1897-4287-9-S1-05

Cite this article as: O'Malley et al.: The prevalence of hereditary

hemorrhagic telangiectasia in Juvenile Polyposis syndrome patients with SMAD4 mutations. Hereditary Cancer in Clinical Practice 2011

9(Suppl 1):05.

Submit your next manuscript to BioMed Central and take full advantage of:

- Convenient online submission

- Thorough peer review

- No space constraints or color figure charges

- Immediate publication on acceptance

- Inclusion in PubMed, CAS, Scopus and Google Scholar

- Research which is freely available for redistribution

Submit your manuscript at www.biomedcentral.com/submit
C Biomed Central 